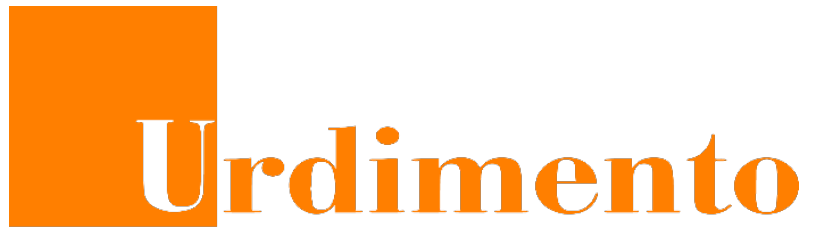

REVISTA DE ESTUDOS EM ARTES CÊNICAS

E-ISSN 2358.6958

\title{
Viewpoints como estrutura para a encenação: Reflexões a partir de uma experiência
}

Marcella Vicentini Cerbara

\section{Para citar este artigo:}

CERBARA, Marcella Vicentini. Viewpoints como estrutura para a encenação: Reflexões a partir de uma experiência. Urdimento - Revista de Estudos em Artes Cênicas, Florianópolis, v. 3, n. 42, dez. 2021.

doi DOI: http:/dx.doi.org/10.5965/1414573103422021e0107

Este artigo passou pelo Plagiarism Detection Software| iThenticate 
Viewpoints como estrutura para a encenação:

Reflexões a partir de uma experiência ${ }^{1}$

Marcella Vicentini Cerbara²

\title{
Resumo
}

O presente artigo reflete sobre o processo de ensaio do espetáculo Chiquita Bacana no Reino das Bananas, dirigido por Dagoberto Feliz, com o Grupo Folias D'arte, a partir de uma análise dos principais procedimentos inspirados no Livro dos Viewpoints: um guia prático para Viewpoints e Composição, escrito por Anne Bogart e Tina Landau. O objetivo é entender como a Técnica de Viewpoints pode apontar caminhos para a atuação e proporcionar uma estrutura para a encenação do espetáculo.

Palavras-chave: Viewpoints. Processo de ensaio. Grupo Folias D’arte.

\section{Viewpoints as a structure for staging: Reflections from an experience}

\begin{abstract}
This article reflected on the rehearsal process of the show Chiquita Bacana no Reino das Bananas (Chiquita Bacana in the kingdom of bananas), directed by Dagoberto Feliz, with Grupo Folias D'arte. From an analysis of the main procedures inspired by the Book of Viewpoints - A Practical Guide to Viewpoints and Composition, written by Anne Bogart and Tina Landau. This article aims at understanding how the Viewpoints Technique pointed out paths for acting and provided a structure for staging the show.
\end{abstract}

Keywords: Viewpoints. Testing process. Group Folias D'arte.

1 Revisão ortográfica e gramatical do artigo realizada por Clarisse Lyra. Mestra em Letras pela Universidade de São Paulo (FFLCH-USP).

${ }^{2}$ Mestre em Literatura e Crítica Literária pela Pontifícia Universidade Católica de São Paulo (PUC-SP). Licenciatura em Português pela mesma universidade. marcella.vicentini7@gmail.com

(9) http://lattes.cnpq.br/4254114032906487 (iD https://orcid.org/0000-0002-8068-0688 
Los puntos de vista como estructura de la puesta en escena: Reflexiones desde una experiencia

\section{Resumen}

Este artículo reflexiona sobre el proceso de ensayo del espectáculo Chiquita Bacana en el Reino de Bananos (Chiquita Bacana no reino das bananas), dirigido por Dagoberto Feliz, con el Grupo Folias D'arte. A partir de un análisis de los principales procedimientos inspirados en el Libro de los viewpoints: una guía práctica de los puntos de vista y composición, escrito por Anne Bogart y Tina Landau. El objetivo aquí era comprender cómo la técnica de los puntos de vista señaló caminos para la actuación y proporcionó una estructura para la puesta en escena del espectáculo.

Palabras clave: Viewpoints. Proceso de ensayo. Grupo Folias D'arte. 


\section{Introdução}

Pisar no palco deve ser como pular do trampolim mais alto de uma piscina olímpica (Bogart, 2007. p.34). ${ }^{3}$

A frase acima, presente no livro And Then, you act, escrito pela diretora Anne Bogart, traz uma poderosa imagem que traduz a sensação de estar em cena. Ao pisar no palco, saltamos de um trampolim, e o exato instante que precede o ato é o risco e a instabilidade. Anne Bogart e Tina Landau são criadoras de O Livro dos Viewpoints: um guia prático para Viewpoints e composição. Viewpoints é uma técnica de improvisação inicialmente criada pela coreógrafa Mary Overlie, na década de 1970, e posteriormente desenvolvida por Anne Bogart para o processo de criação do/a ator/atriz. Trata-se da articulação de focos de atenção por parte do praticante durante a improvisação. Neste artigo, pretendo refletir sobre como a técnica de Viewpoints apontou caminhos para a atuação durante o processo de criação e ainda proporcionou uma estrutura para a encenação do espetáculo Chiquita Bacana no Reino das Bananas, dirigido por Dagoberto Feliz com o Grupo Folias D'Arte.

Minha experiência com a Técnica de Viewpoints teve início em dois lugares simultaneamente: no curso do Núcleo Experimental de Artes Cênicas do SESI, na época coordenado por Miriam Rinaldi, no qual, durante o ano de 2015, tivemos aulas de Viewpoints duas vezes na semana; e no decorrer da minha pesquisa de mestrado, em que analiso a importância do Viewpoints como procedimento usado no espetáculo Gaivota: tema para um conto curto, dirigido por Enrique Díaz.

Desde então, venho atuando como preparadora corporal de diversas peças ao lado do diretor e ator Dagoberto Feliz. Nesses trabalhos, conduzo um treino a partir da técnica de Viewpoints durante os ensaios. Cada trabalho apresenta suas especificidades, variando o número de atores/atrizes, o tempo de ensaio, o espaço e o material poético utilizado. Durante a condução, apoio-me principalmente em exercícios descritos em O Livro dos Viewpoints. Neste livro, o capítulo intitulado 
"Os Viewpoints no ensaio" reflete sobre os benefícios de se usar os Viewpoints no processo de ensaio, que, segundo as autoras, "é um processo complexo e muda de acordo com o material, o ponto de vista do diretor e/ou do dramaturgo e as dinâmicas do elenco" (Bogart e Landau, 2017, p.146).

No final de 2015, fui convidada pelo diretor Dagoberto Feliz para fazer a preparação corporal do espetáculo infantil Chiquita Bacana no Reino das Bananas, escrito por Reinaldo Maia em 1977. O texto traz à narrativa um reino animal em que uma menina é levada a julgamento por ter comido uma banana no reino das bananas. Ao final do espetáculo, é aberto um espaço de debate em que as crianças podem decidir juntas como terminar a trama. A peça estreou em 12 de março de 2016 e recebeu, nesse mesmo ano, o Prêmio APCA de Melhor Espetáculo Interativo, além de ter sido indicado ao Prêmio SP de Teatro Infantil e Jovem na categoria Melhor Trilha Adaptada.

Essa foi minha primeira experiência na condução da prática de Viewpoints como ferramenta de preparação corporal para um espetáculo. Depois dela, seguiram-se outras, nos espetáculos Rasto Atrás e Dragão Dourado, novamente dirigidos por Dagoberto Feliz, Erêndira, peça dirigida por Marco Antônio Rodrigues em cartaz no teatro do SESI em São Paulo, e Jornada de um Imbecil até o entendimento, dirigida por Hélio Cícero. Neste artigo, escolhi analisar o processo de Chiquita Bacana no Reino das Bananas, pois, tendo sido essa a minha primeira experiência, considero-a decisiva. Ainda hoje me pergunto: quais foram as reverberações da técnica de Viewpoints na construção da encenação? Como a prática coletiva se refletiu no jogo dos/das atores/atrizes e como afetou as escolhas do diretor durante o processo de ensaio?

\section{Tempo}

Durante três meses, conduzi a prática dos Viewpoints levando em consideração o primeiro aspecto ao aplicá-la na sala de ensaio: o tempo. espetáculo em questão foi parte do projeto 15 anos/ 100 anos. Solidão e Galpão. Cada teatro tem os fantasmas que deseja, contemplado pela vigésima sétima edição do prêmio Lei de Fomento ao Teatro para a cidade de São Paulo. Como em 
todos os editais de fomento, o projeto possui um tempo definido para início e término, e nos últimos meses é preciso cumprir com o total de apresentações prometido. Nesse caso, o cronograma de trabalho foi de três meses de ensaios seguidos de três meses de temporada. O tempo em sala de ensaio foi dividido entre o estudo de Viewpoints, coordenado por mim com o auxílio da atriz Clarissa Moser, e as questões do texto e do levantamento das cenas, conduzidas pelo diretor. Apesar de o ensaio ter sido dividido dessa forma, participei, acompanhando e observando ao lado de Dagoberto, as atividades da segunda parte, e ele muitas vezes também estava presente, observando e interferindo, durante a prática de Viewpoints. Dessa forma, criou-se um diálogo permanente entre a preparação corporal e a direção.

Chiquita Bacana no Reino das Bananas contou com um elenco de treze atores/atrizes, dos quais metade era composta por convidados. Levando em consideração que, nesse processo, a maioria dos/as atores/atrizes nunca havia trabalhado conjuntamente, e que muitos nunca tinham praticado Viewpoints, as primeiras semanas foram dedicadas à introdução básica do sistema. Aos poucos, o elenco foi se familiarizando com o vocabulário usado durante os exercícios, criando um léxico comum para apontar e refletir sobre questões de tempo e espaço na cena.

Durante o primeiro momento, tivemos a intenção de criar um coletivo. Os exercícios iniciais propostos por Anne Bogart e Tina Landau ajudam os/as atores/atrizes a se conectarem uns com os outros, pois têm como princípio a relação e a "escuta extraordinária", que "significa escutar com o corpo inteiro sem a ideia de um resultado" (Bogart e Landau, 2017, p.52). O que importa é o que acontece "entre" os/as atores/atrizes. Esse deslocamento, aparentemente simples, do foco de atenção provoca o jogador a olhar continuamente para fora de si e abrir a escuta para o coletivo.

Muitos dos exercícios propostos nessa fase inicial engajaram os/as atores/atrizes a realizarem tarefas em conjunto durante uma improvisação. Como exemplo, um dos exercícios realizados diversas vezes foi o doze/seis/quadro, que consiste em um jogo no qual os participantes permanecem correndo em roda e têm de realizar juntos algumas ações sem que ninguém lidere, tais como: concluir 
seis pulos, três mudanças de direção e uma súbita parada. Cada vez que o grupo tentava realizar uma delas, a relação entre eles ficava mais interessante para quem assistia. É importante ressaltar que, principalmente no início, os/as atores/atrizes não conseguiram realizar as tarefas propostas no enunciado. Foi possível observar momentos em que tinham a intenção de resolver sozinhos o desafio, em vez de coletivamente, forjando o acontecimento. Nesse espetáculo, o grupo foi composto por jovens artistas com diferentes formações, que chegaram ao processo com suas limitações e experiências individuais. Só depois de repetir algumas vezes o exercício, foi possível perceber uma escuta mais atenta entre o coletivo.

A proposição exige uma complexa integração entre os participantes: é preciso equalizar o ímpeto de liderar a ação e o desejo de se deixar levar pelo todo. O trabalho não consiste apenas em realizar três mudanças de direção individualmente, mas em realizá-las ao mesmo tempo, sem que ninguém force o acontecimento, exigindo do/a ator/atriz que permaneça atento/a ao momento presente. Ao mesmo tempo, trata-se de um modo de pressionar o deslocamento da percepção de cada participante, de um tempo-espaço próprio ou individual para um tempo-espaço compartilhado - ou criado coletivamente.

\section{Criar um vocabulário físico para a peça}

Nas primeiras semanas de ensaio, já com as personagens distribuídas entre o elenco, iniciamos a pesquisa dos gestos específicos de cada personagem da peça Chiquita Bacana no Reino das Bananas. O gesto, em Viewpoints, é compreendido como um movimento com começo, meio e fim que pode envolver uma ou mais partes do corpo. Segundo Anne Bogart e Tina Landau, existem dois tipos de gesto: o comportamental e o expressivo (Bogart e Landau, 2017). O gesto comportamental pertence à realidade cotidiana: são gestos que vemos na rua, no supermercado, no metrô, e que fazem parte do mundo físico do comportamento humano. Já os gestos expressivos são aqueles que exprimem um estado interno, um desejo ou ideia. Cada ator/ atriz pesquisou e escolheu cinco gestos para seu personagem e os explorou em diferentes andamentos, experimentando quão rápida ou quão lenta poderia ser determinada ação. 
É importante salientar que, na proposta, não havia um gesto que fosse considerado certo ou errado, apenas escolhas a serem feitas de maneira física. Em seguida, realizamos o Trabalho na Raia, que consiste em um exercício em que cinco participantes formam uma linha horizontal de frente para a plateia. Imaginemos uma piscina onde cada pessoa se desloca na sua raia, podendo apenas: andar para frente e para trás; realizar um dos gestos; variar o andamento; repetir o gesto de outra pessoa; ou parar. Além disso, os participantes trabalham com a resposta cinestésica: "o movimento de uma pessoa começa somente em resposta ao movimento de outra pessoa" (Bogart e Landau, 2017, p.91).

Esse trabalho na raia propõe que o/a ator/atriz encontre liberdade ao lidar com restrições. O enunciado indica que o participante pode realizar apenas algumas ações, limitando suas escolhas. Como apontam as autoras (Bogart e Landau, 2017), estar totalmente comprometido com uma ação, mas, ainda assim, aberto a qualquer mudança, é um paradoxo físico que leva a uma sensação de liberdade.

Figura 1 - Os atores: Clarissa Moser, Tarcila Tanhã, Thomas Basso e Camila Spinella em cena do espetáculo Chiquita Bacana no Reino das Bananas. Foto: Cacá Bernardes

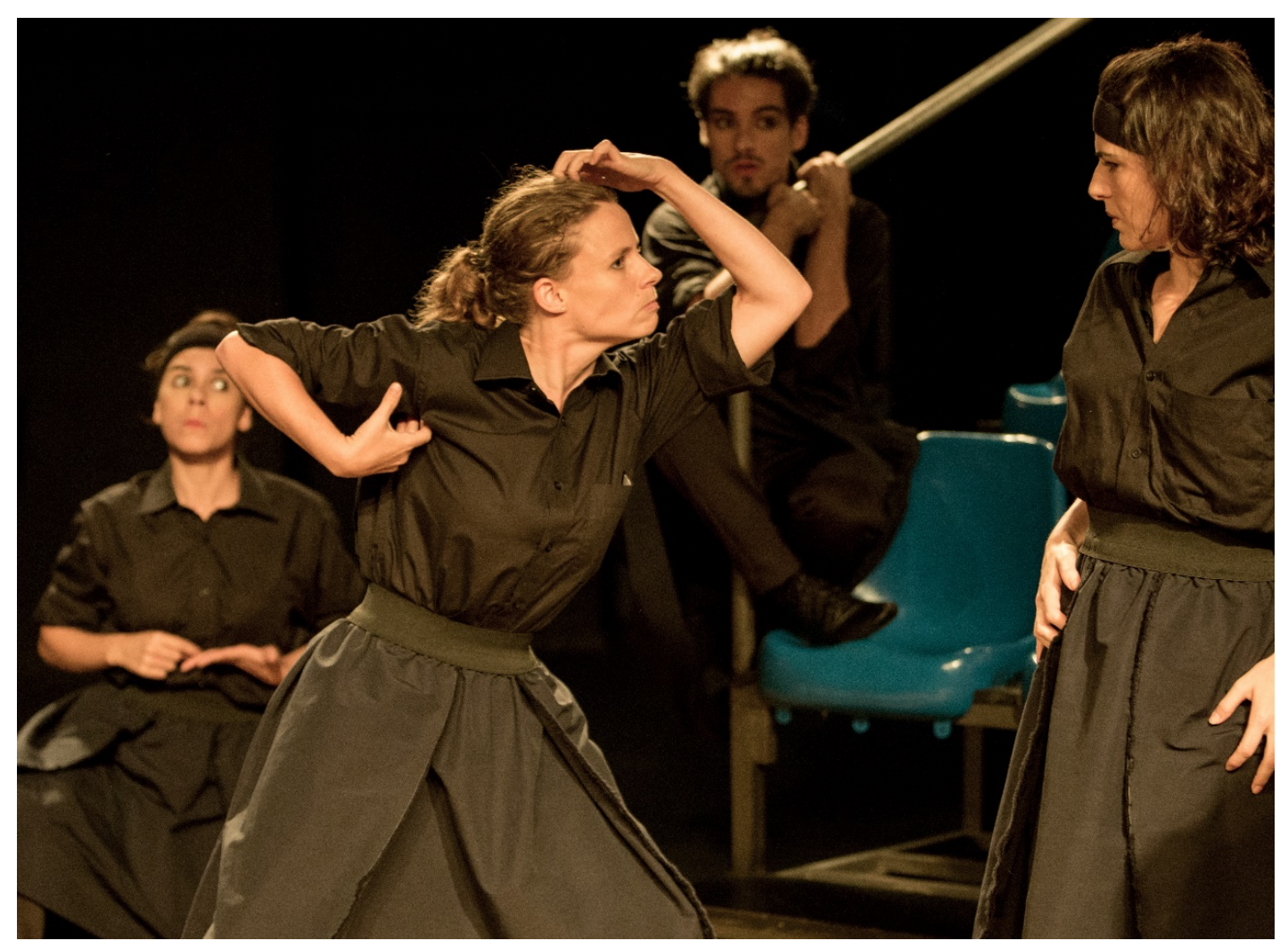

Fonte: Divulgação. 
Aos poucos, ao repetir algumas vezes o trabalho na raia, todo o grupo aprendeu uma grande quantidade de gestos diferentes. Os gestos escolhidos e pesquisados foram sendo inseridos pelo elenco diretamente na cena, formando um vocabulário físico para o espetáculo. Durante os ensaios com o diretor, os/as atores/atrizes realizavam os gestos dentro da circunstância da narrativa, o que fazia com que ganhassem novos sentidos, fosse por meio do texto ou pela relação com o outro/a ator/atriz. Dessa forma, os gestos foram organicamente sendo repetidos na construção dos possíveis caminhos de cada cena. O ator Marcellus Beghelle, que representou a personagem do coelho, relata:

Eu me sentia criativo através do Viewpoints. Eu achava que o Viewpoints era uma ferramenta muito grande para a minha criatividade poder fluir. Eu tive muita facilidade em produzir coisas criativas porque eu sentia no Viewpoints muita liberdade. Mesmo com as regras que ele tem, eu acho que são regras libertadoras. ${ }^{4}$

Tal fala revela uma importante contribuição do Viewpoints no processo de ensaio de um espetáculo: um dispositivo de criação. O/a ator/atriz se apoia no tempo, no espaço e nos outros corpos presentes. A criação passa a ser algo construído coletivamente, e não resultado de uma habilidade individual. Tudo o que foi criado pode ser apropriado por todos e transformado durante essa apropriação. Nesse processo, as improvisações de Viewpoints adequaram-se perfeitamente àquilo que Dagoberto Feliz buscava: não criar marcas que os/as intérpretes devessem reproduzir, mas estimular que o coletivo determinasse como o espaço deveria ser ocupado. Há, implícita, portanto, uma concepção de que o trabalho do/da ator/atriz é uma criação altamente arriscada, se considerarmos o alto grau de instabilidade das improvisações presentes tanto no processo de montagem quanto na cena do espetáculo.

\section{Espaço}

O Galpão do Folias, localizado em São Paulo no bairro de Santa Cecília, possui quatro arquibancadas móveis que, para esse espetáculo, formaram uma pequena

${ }^{4}$ Entrevista concedida à autora por e-mail em junho de 2021 (inédita), 
arena. No centro dessa arena, uma lona de caminhão e quatro holofotes definiram o espaço cênico. A luz geral permanecia acesa, permitindo que elenco e plateia se vissem durante a performance inteira. Os únicos objetos eram uma cadeira de ferro e um pedestal de microfone. O espaço não possui coxias, e os/as atores/atrizes não saíam de cena. O figurino de cor preta era igual para todo o elenco: uma camisa, uma calça com uma saia por cima e uma sapatilha.

Figura 2 - Os atores Bruno Camargo, Camila Spinella Vaz, Clarissa Moser, Gabriel Hirschhorn, Juliana Tedeschi, Laruama Alves, Leandro Goulart, Lui Seixas, Marcellus Beghelle, Rafael Sampaio, Tarcila Tanhã e Thomas Basso momentos antes de o espetáculo Chiquita Bacana no Reino das Bananas começar. Foto: Victor Lemini

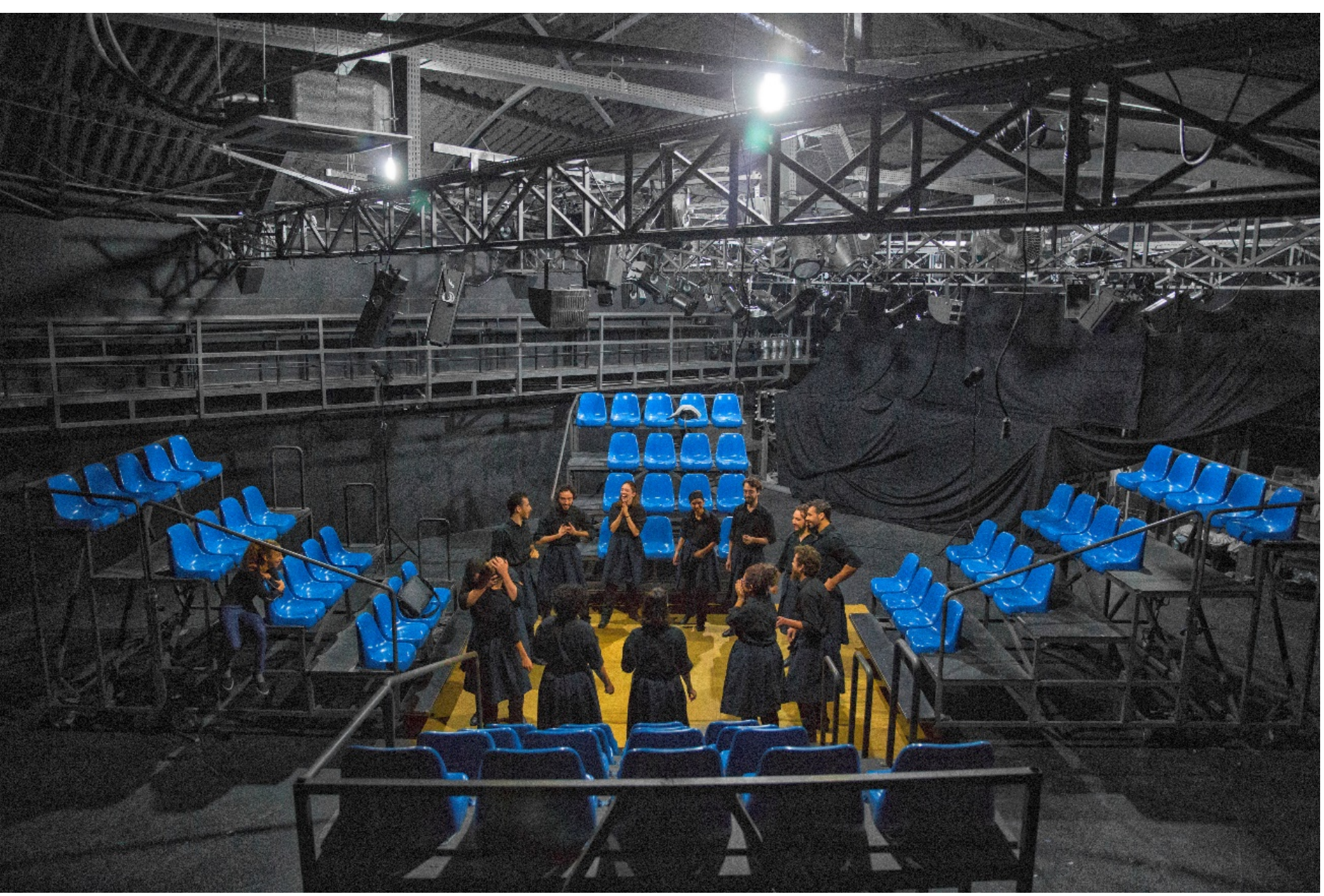

Fonte: Divulgação.

Ao trabalhar com o Viewpoints de Relação espacial, pedimos que os 
participantes caminhassem pelo espaço colocando seu foco de atenção na distância entre eles, investigando as possibilidades de diminuir ou aumentar essa distância. Segundo Bogart e Landau, em nossa vida cotidiana, mantemo-nos a uma distância confortável, de um ou dois metros, uns dos outros. Em cena, quando começamos a manipular esse espaço, "começamos a criar dinâmica, evento, relacionamento" (Bogart e Landau, 2017, p.65). Em seguida, acrescentamos o Viewpoints de Arquitetura. Nesse momento, o elenco pesquisou inúmeras maneiras de ocupar o espaço cênico coletivamente. Pedimos para que focassem a atenção na arquitetura, abrindo a percepção para o espaço cênico como um todo e se colocando em relação com a textura, a luz/sombra, as cores e as matérias ali presentes.

Esse exercício, que põe em foco o espaço, fez com que os/as atores/atrizes descobrissem lugares antes inexplorados, como a possibilidade de ocupar a plateia, a parte traseira das arquibancadas, as escadas do teatro, e não apenas a área do palco. Essa consciência foi fundamental para o grupo, já que, no espetáculo, não existem marcas definidas; os/as atores/atrizes, durante a performance inteira, fazem escolhas sobre suas posições no espaço. Tais escolhas levam em consideração a relação entre os jogadores e a arquitetura presente. No programa do espetáculo, Dagoberto Feliz escreveu:

Lá pelos idos de 1990 e poucos o Reinaldo Maia propunha um exercício básico para nós, atores. Entrar na lona (tapete) para contar uma história. Parece simples, não? Não era. Não é. Chiquita Bacana no Reino das Bananas foi o texto escolhido para levantarmos essas questões na cena. ${ }^{5}$

Como aponta o diretor, o exercício de entrar em cena e contar uma história sem nenhum recurso além do próprio corpo é algo básico no teatro, mas não é algo simples. Por meio da prática do Viewpoints, ao manipular o tempo e o espaço, foi possível tornar perceptível aos/às atores/atrizes o fato de haver inúmeras possibilidades dentro de um espaço vazio. A escolha de Dagoberto de usar somente uma lona no chão, um figurino igual para todos/as e uma iluminação estática acaba por enfatizar um elemento fundamental do teatro: a relação entre 
os jogadores.

\section{Mudando de lugar no espaço}

O exercício "Mudando de lugar no espaço" é descrito da seguinte forma: uma pessoa por vez deve entrar no espaço e se posicionar formando uma composição interessante. As decisões de onde se colocar são tomadas considerando os outros e a arquitetura (Bogart e Landau, 2017). Depois que todos os jogadores tiverem escolhido um lugar, é pedido para que memorizem a posição. Em seguida, mudam de lugar no espaço novamente. Ao total, são memorizadas três posições diferentes. A improvisação então acontece com os participantes passando de uma posição a outra, usando os Viewpoints. Esse é um dos exercícios de improvisação usados durante o treino e aplicado diretamente na primeira cena do espetáculo Chiquita Bacana no Reino das Bananas. Nessa cena, o elenco canta a música Chiquita Bacana enquanto transita pelo palco. As três posições de cada ator/atriz se repetem no espaço, mas o jogo que acontece entre uma posição e outra é diferente a cada apresentação, pois depende da dinâmica do grupo a cada dia.

Vale apontar que Anne Bogart não utiliza o Viewpoints diretamente ligado a um espetáculo. Segundo o pesquisador Fabiano Lodi, "Bogart desvincula o treinamento da produção artística, conferindo-lhe importância fora da esfera dos resultados imediatos" (Lodi, 2015, p.58). Apesar disso, no processo de Chiquita Bacana no Reino das Bananas, utilizamos a técnica também com a intenção de descobrir possíveis caminhos para a encenação. Neste caso, o exercício usado ajudou diretamente na organização da cena. Não foi preciso coreografar os movimentos de cada ator/atriz para que o grupo se movesse pelo palco de forma consciente e expressiva e, contudo, de modo diferente a cada apresentação.

\section{O jogo da encenação: um salto no abismo}

Depois de levantadas todas as cenas, e contrariando todo o trabalho feito até então, Dagoberto Feliz anunciou para o elenco que a peça não teria personagens definidos: eles seriam sorteados pela plateia no início do espetáculo, de forma que 
todos poderiam fazer qualquer personagem, independentemente das definições de gênero. Aquilo que cada um havia criado até ali seria uma possibilidade de vocabulário físico. Ou seja, quem viesse a sortear determinado personagem, mesmo que nunca o tivesse ensaiado, poderia repetir o que já tinha visto outra pessoa fazer. Essa repetição se daria a seu próprio modo, claro, já que a repetição nunca é exata. Em entrevista, a atriz Tarcila Tanhã declarou: "A proposição de cada ator fazia com que a gente experimentasse outros corpos, outras particularidades, que certamente estavam fora da zona de conforto individual". ${ }^{6}$ Quando um/a ator/atriz repetia o gesto de outro/a, permitia-se experimentar uma maneira de agir fisicamente diferente da sua, já que a criação não tinha sido feita por ele/ela.

Figura 3 - O ator Rafael Sampaio em cena no espetáculo Chiquita Bacana no Reino das Bananas. Foto: Cacá Bernardes

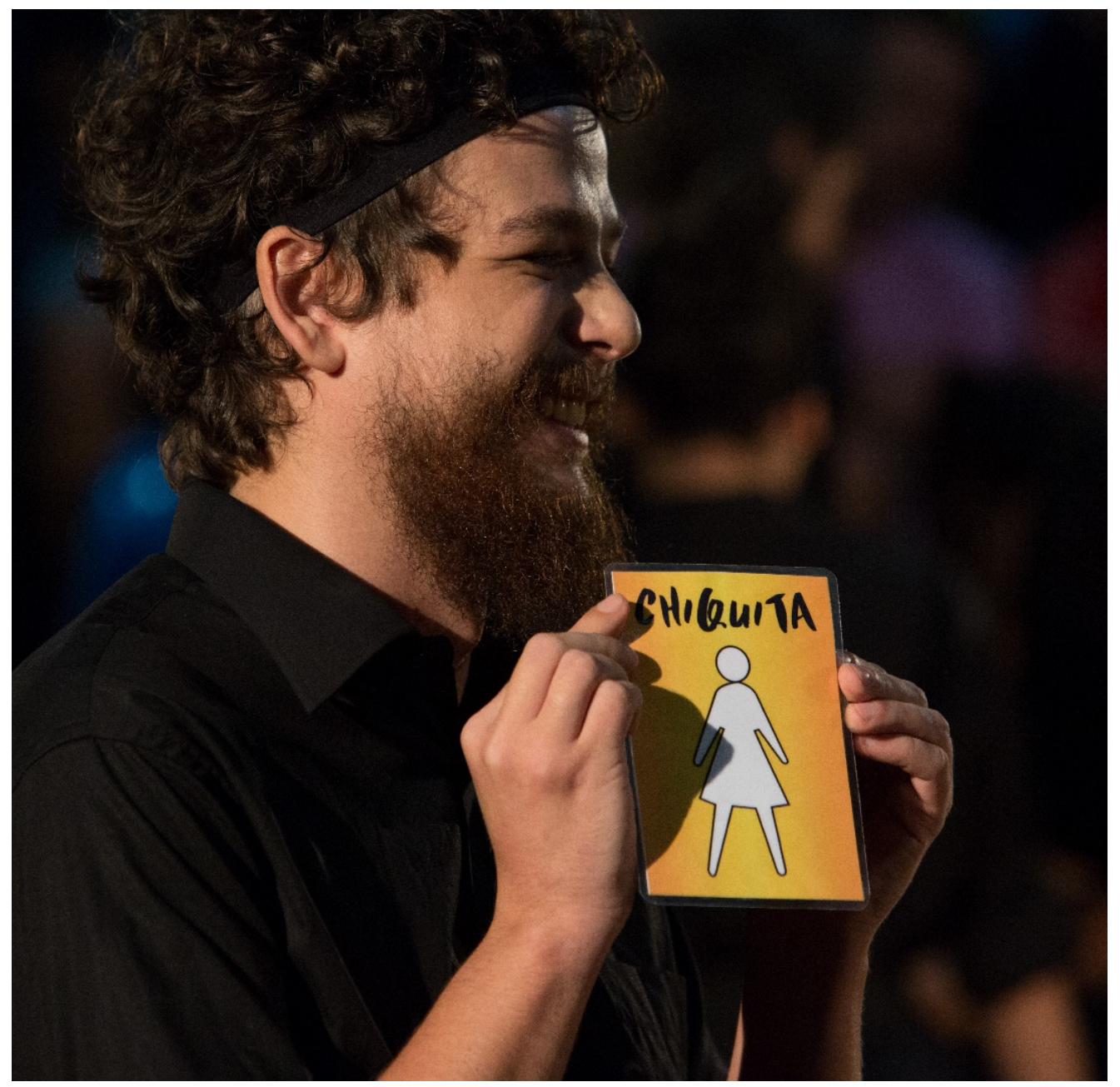

Fonte: Acervo da fotógrafa Cacá Bernardes.

${ }^{6}$ Entrevista concedida à autora por e-mail em junho de 2021 (inédita). 
Chiquita Bacana no Reino das Bananas ficou em cartaz durante três meses no Galpão do Folias. Em seguida, participou de festivais, esteve no teatro do Itaú Cultural, no Teatro de Contêiner da Cia Mugunzá e em diversos SESC no Estado de São Paulo. As possibilidades de combinações de personagens entre o elenco são inúmeras. O fato de os/as atores/atrizes não terem um personagem definido torna o espetáculo totalmente diferente a cada apresentação. Ainda que o texto permaneça o mesmo, a mudança de intérprete na representação dos personagens e a ausência de marcas ou de uma coreografia determinada de ocupação do espaço fazem com que o jogo cênico mude drasticamente, tornando-se irrepetível. O elenco tem de estar completamente atento, já que não sabe qual personagem será sorteado pelo outro até o início da peça. No decorrer das apresentações, os/as atores/atrizes muitas vezes sorteavam um personagem pela primeira vez, mesmo estando há semanas em cartaz.

Dagoberto Feliz diz que sempre teve vontade de realizar um espetáculo em que o elenco soubesse todo o texto e pudesse revezar os personagens:

O Viewpoints corroborou e apontou caminhos reais para que existissem várias versões de personagens, não só entre o elenco, mas também para que cada ator/atriz fizesse a personagem de forma diferente a cada apresentação pela relação com cada um a cada dia. São possibilidades infinitas. Talvez, muito talvez, ainda não haja conceituação para provar que a personagem só existe na relação. Logo, se, por acaso, na Chiquita, só um ator/atriz trocasse, isso afetaria, e tem que afetar, toda a estrutura. ${ }^{7}$

O Viewpoints, por ser uma técnica de improviso, reforçou o exercício dos atores de estarem presentes no aqui-agora da cena, ocupando coletivamente o espaço, abrindo a escuta do corpo e deixando-se afetar pelo outro. Além disso, a prática abriu um espaço em que foi possível gerar material, como um repertório físico para os/as atores/atrizes, ao mesmo tempo que estimulou uma dinâmica não hierárquica entre o elenco e a direção. Em Chiquita Bacana no Reino das Bananas, o/a ator/atriz precisa estar continuamente aberto a mudanças, já que nada, exceto a dramaturgia, é definitivo. Dessa forma, a dinâmica proposta pelo diretor acabou por potencializar o risco e a instabilidade, elementos inerentes ao

${ }^{7}$ Entrevista concedida à autora por e-mail em junho de 2021 (inédita). 
fazer teatral. Por isso, acredito que, no espetáculo, o sistema de Viewpoints aparece não como um caminho para a encenação, e, sim, como seu próprio fundamento. Os/as atores/atrizes aprenderam um vocabulário em comum e passaram a ter liberdade de comunicação criativa, tornando-se cocriadores da obra. Por meio da técnica, o grupo experimentou um modo de pensar e agir em cena. Viewpoints é a linguagem comum que baseia o jogo dos atores/atrizes, já que tudo está para ser decidido entre os jogadores a cada apresentação.

Em entrevista presente no vídeo What's the Story: Essays about Art, Theater, and Storytelling(Bogart, 2014), Anne Bogart diz acreditar que o teatro cria pequenas sociedades e que o Viewpoints propõe uma nova maneira, mais horizontal, de as pessoas se relacionarem. Ao assistir Chiquita Bacana no Reino das Bananas, a plateia presencia a narrativa de uma menina julgada por comer uma banana em um país abundante em bananas, discutindo as relações de poder de um governo autoritário. Ao mesmo tempo, por intermédio dos Viewpoints, a estrutura da peça propõe uma maneira horizontal de relação entre os/as atores/atrizes. Essa relação se estende para a plateia, que ajuda a construir, inclusive, o fim da narrativa. Assim, ao mesmo tempo que a fábula discute o presente de uma sociedade que poderia ser a nossa, o espetáculo propõe uma nova possibilidade de futuro: uma maneira mais igualitária de relação entre as pessoas que se inventa naquele momento.

\section{Referências}

BEGHELLE, Marcellus; TANHÃ, Tarcila; Feliz, Dagoberto. Entrevista concedida a Marcella Vicentini Cerbara por e-mail. São Paulo. (Inédita).

BOGART, Anne. What's the Story. Essays about Art, Theater, and Storytelling. The Graduate Center, CUNY. 2014. Disponível em: https://www.youtube.com/watch?v=v431KIvSo8c\&ab_channel=TheGraduateCente r\%2CCUNY. Acesso em 7 nov. 2021.

BOGART, Anne. And then, you act: making art in an unpredictable world. Nova York: Routledge, 2007.

BOGART, Anne; LANDAU, Tina. O Livro dos Viewpoints: um guia prático para Viewpoints e composição. São Paulo: Perspectiva, 2017. 
FELIZ, Dagoberto. Programa Chiquita Bacana no Reino das Bananas. Direção de Dagoberto Feliz. Acervo do Grupo Folias D’Arte. São Paulo: Galpão do Folias, 2013.

LODI, Fabiano. Direção teatral na perspectiva de Anne Bogart. 2015. Dissertação (Mestrado). Universidade Estadual Paulista Júlio de Mesquita Filho, Instituto de Artes, 2015.

Recebido em: 15/08/2021

Aprovado em: 23/11/2021 